\title{
Spatial distribution of transcript changes in the maize primary root elongation zone at low water potential
} William G Spollen ${ }^{1,8}$, Wenjing Tao ${ }^{1,9}$, Babu Valliyodan ${ }^{1}$, Kegui Chen ${ }^{1}$, Lindsey G Hejlek ${ }^{1}$, Jong-Joo Kim ${ }^{2,7,10}$, Mary E LeNoble ${ }^{1}$, Jinming Zhu', Hans J Bohnert ${ }^{4,5}$, David Henderson'2,11, Daniel P Schachtman ${ }^{6}$, Georgia E Davis ${ }^{1}$, Gordon K Springer ${ }^{3}$, Robert E Sharp ${ }^{1}$ and Henry T Nguyen*1

\footnotetext{
Address: ${ }^{1}$ Division of Plant Sciences, University of Missouri, Columbia, MO 65211, USA, ${ }^{2}$ Department of Animal Science, University of Arizona Tucson, Arizona 85721, USA, ${ }^{3}$ Department of Computer Science, University of Missouri, Columbia, MO 65211, USA, ${ }^{4}$ Department of Plant Biology and Department of Crop Sciences, University of Illinois at Urbana-Champaign, Urbana, IL 61801, USA, ${ }^{5}$ W. M. Keck Center for Comparative and Functional Genomics, University of Illinois at Urbana-Champaign, Urbana, IL 61801, USA, ${ }^{6}$ Donald Danforth Plant Science Center, St. Louis, Missouri 63132, USA, ${ }^{7}$ School of Biotechnology, Yeungnam University, Gyeongsan, Gyeongbuk, 712749 South Korea, 8 Research Support Computing, University of Missouri, Columbia, MO 65211, USA, ${ }^{9}$ Bio-Rad Laboratories, 2000 Alfred Nobel Drive, Hercules, CA 94547, USA, ${ }^{10}$ School of Biotechnology, Yeungnam University, Gyeongsan, Gyeongbuk, 712749 South Korea and ${ }^{11}$ Insightful Corporation, Seattle, WA 98109, USA

Email: William G Spollen - spollenw@missouri.edu; Wenjing Tao - taowenjing@hotmail.com; Babu Valliyodan - valliyodanb@missouri.edu; Kegui Chen - chenkeg@missouri.edu; Lindsey G Hejlek - hejlekl@missouri.edu; Jong-Joo Kim - kimjj@yumail.ac.kr; Mary E LeNoble - lenoblem@missouri.edu; Jinming Zhu - zhuj@missouri.edu; Hans J Bohnert - bohnerth@life.uiuc.edu; David Henderson - DNADave@Insightful.Com; Daniel P Schachtman - dschachtman@ danforthcenter.org; Georgia E Davis - davisge@missouri.edu; Gordon K Springer - springer@missouri.edu; Robert E Sharp - sharpr@missouri.edu; Henry T Nguyen* - nguyenhenry@missouri.edu

* Corresponding author
}

Published: 3 April 2008

BMC Plant Biology 2008, 8:32 doi:10.1 I86/147I-2229-8-32
Received: 31 December 2007

Accepted: 3 April 2008

This article is available from: http://www.biomedcentral.com/I47I-2229/8/32

(C) 2008 Spollen et al; licensee BioMed Central Ltd.

This is an Open Access article distributed under the terms of the Creative Commons Attribution License (http://creativecommons.org/licenses/by/2.0), which permits unrestricted use, distribution, and reproduction in any medium, provided the original work is properly cited.

\begin{abstract}
Background: Previous work showed that the maize primary root adapts to low $\Psi_{w}(-1.6 \mathrm{MPa})$ by maintaining longitudinal expansion in the apical $3 \mathrm{~mm}$ (region I), whereas in the adjacent $4 \mathrm{~mm}$ (region 2) longitudinal expansion reaches a maximum in well-watered roots but is progressively inhibited at low $\Psi_{\mathrm{w}}$. To identify mechanisms that determine these responses to low $\Psi_{\mathrm{w}}$, transcript expression was profiled in these regions of water-stressed and well-watered roots. In addition, comparison between region 2 of water-stressed roots and the zone of growth deceleration in wellwatered roots (region 3 ) distinguished stress-responsive genes in region 2 from those involved in cell maturation.

Results: Responses of gene expression to water stress in regions I and 2 were largely distinct. The largest functional categories of differentially expressed transcripts were reactive oxygen species and carbon metabolism in region I, and membrane transport in region 2. Transcripts controlling sucrose hydrolysis distinguished well-watered and water-stressed states (invertase vs. sucrose synthase), and changes in expression of transcripts for starch synthesis indicated further alteration in carbon metabolism under water deficit. A role for inositols in the stress response was suggested, as was control of proline metabolism. Increased expression of transcripts for wall-
\end{abstract}


loosening proteins in region I, and for elements of $A B A$ and ethylene signaling were also indicated in the response to water deficit.

Conclusion: The analysis indicates that fundamentally different signaling and metabolic response mechanisms are involved in the response to water stress in different regions of the maize primary root elongation zone.

\section{Background}

Water supply limits crop productivity more than any other abiotic factor [1], and the ability of plant roots to find and extract water in drying soil can determine plant reproductive success and survival. Indeed, the adaptation of roots to counteract a limiting water supply is highlighted by the fact that root growth is often less sensitive to water deficit than shoot growth $[2,3]$. Understanding the mechanisms that allow roots to grow at low water potentials $\left(\Psi_{\mathrm{w}}\right)$ should reveal ways to manipulate drought responses and may ultimately improve tolerance.

Progress in understanding the mechanisms that determine root growth at low $\Psi_{\mathrm{w}}$ has been made using a maize seedling system involving precise and reproducible imposition of water deficits $[4,5]$. Root elongation rate under severe water deficit $\left(\Psi_{\mathrm{w}}\right.$ of $\left.-1.6 \mathrm{MPa}\right)$ was about $1 / 3$ the rate of growth at high $\Psi_{\mathrm{w}}(-0.03 \mathrm{MPa})$ [4]. Kinematic analyses detected distinct responses of longitudinal expansion rate to low $\Psi_{\mathrm{w}}$ in different regions of the root growth zone $48 \mathrm{~h}$ after stress imposition when the root elongation rate was at steady state $[4,6]$. Most striking was the complete maintenance of longitudinal expansion rate in the apical 3-mm region of roots growing at low compared to high $\Psi_{\mathrm{w}}$. The adjacent, older, tissue of water-stressed roots decreased expansion rate compared to well-watered roots leading to a shortening of the growth zone.

The biophysical and biochemical bases for the altered growth rate profiles observed in water-stressed roots have been studied (reviewed in [5]). Progressive water deficit induces osmotic adjustment, cell wall loosening, increased ABA accumulation, and membrane hyperpolarization. Little is known about the genes that control these physiologically well documented processes and activities that are involved in the growth response of maize primary roots to severe water deficits. Utilizing the established protocol for stress imposition, we explored the molecular responses to better understand the mechanisms which allowed growth to be maintained in the apical 3-mm but to be inhibited in adjacent older tissues. A maize oligonucleotide microarray was used to identify the differentially expressed transcripts that distinguished well-watered and water-stressed roots in different regions of the root tip in the hopes of delineating the genetic mechanisms responsible for the physiological changes that occur in waterstressed roots and identifying candidate genes that confer the varying growth responses of the different regions of the maize root elongation zone. The results extend some earlier measurements made of gene expression in this system using qRT-PCR by Poroyko et al. [7].

\section{Results and Discussion}

Kinematic analysis was performed on inbred line FR697 to ensure that the spatial profiles of longitudinal expansion rate in primary roots of seedlings growing at high and low $\Psi_{\mathrm{w}}$ were similar to those in the hybrid line used in earlier investigations, and, therefore, that FR697 could be used for genetic analysis in lieu of the hybrid. Similar to the results with the hybrid, four regions of the root tip with distinctly different elongation characteristics were distinguished (Figure 1; [5]). In water-stressed roots, longitudinal expansion rates were the same as in wellwatered roots in the apical $3 \mathrm{~mm}$ (region 1), decelerated in the subsequent $4 \mathrm{~mm}$ (region 2), and ceased in the following $5 \mathrm{~mm}$ (region 3), while in well-watered roots longitudinal expansion rates were maximal in region 2, decelerated in region 3 , and did not cease until $12 \mathrm{~mm}$ from the apex (region 4).

Three pair-wise comparisons were made of transcripts from water-stressed and well-watered tissues in the different root tip regions. In the first comparison (C1), transcripts from region 1 of water-stressed seedlings were compared with those from region 1 of well-watered seedlings. The second comparison (C2) was made between transcripts from region 2 of the two treatments. We expected a larger number of genes to be differentially expressed in region 2 because its elongation rate decreased greatly under water-stressed compared with well-watered conditions. To prioritize the differentially expressed genes revealed in this comparison, a distinction was made between those genes that are associated with growth inhibition in region 2 specifically as a response to water stress, and those genes that are involved in root cell maturation whether under stress or control conditions. A hypothetical example of the former might be genes involved in auxin response since water stress can increase maize root auxin content [8] and application of exogenous auxin can shorten the root growth zone [9]. An example of the latter might involve genes for secondary wall synthesis [10]. To experimentally make this distinction a third pair-wise comparison (C2/3) was included to compare expression of genes between water-stressed region 2 and well-watered 


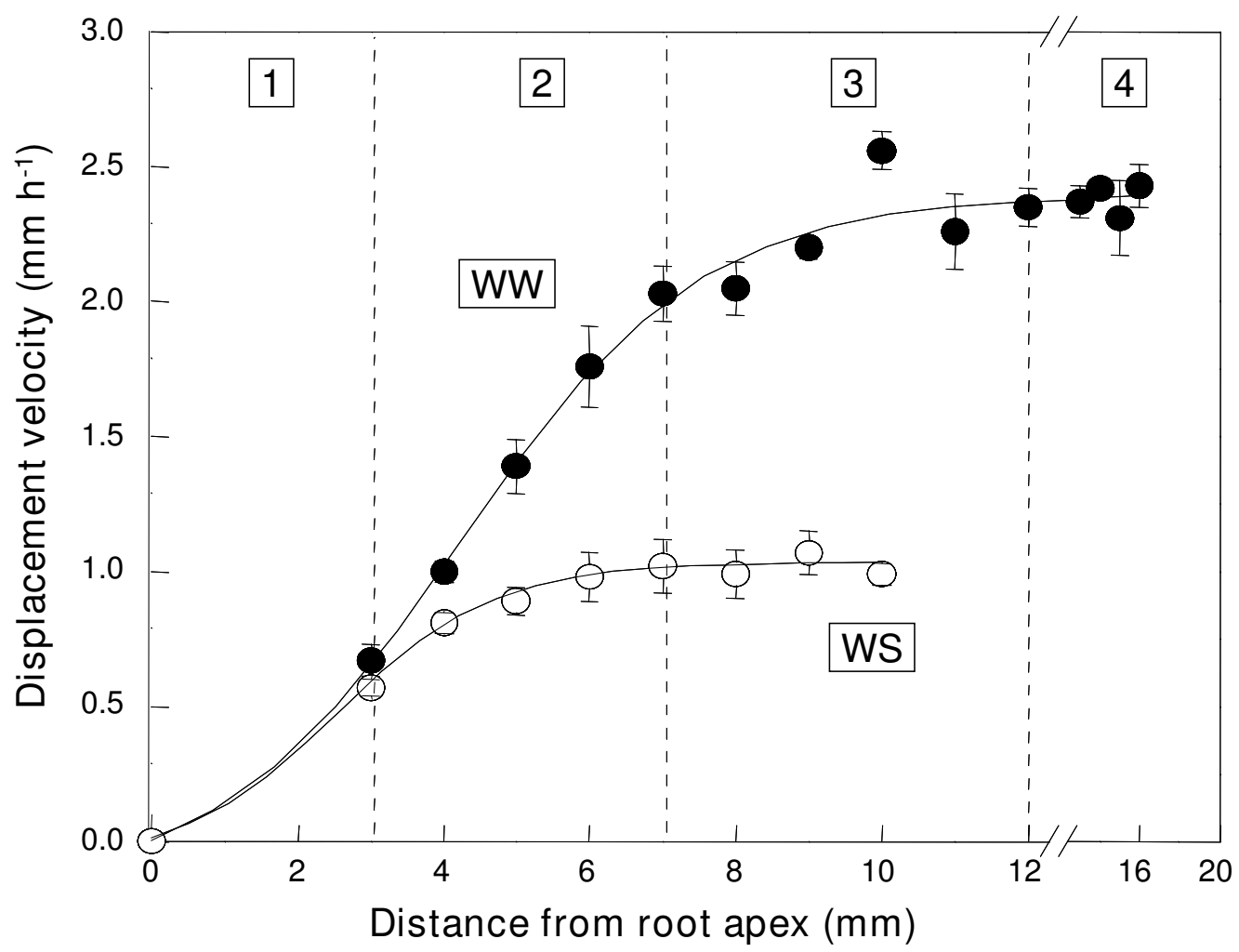

Figure I

Displacement velocity as a function of distance from the root cap junction of primary roots of maize (cv FR697) growing in vermiculite under well-watered (WW; $\Psi_{w}$ of $-0.03 \mathrm{MPa}$ ) or water-stressed (WS; $\Psi_{w}$ of - I.6 $\mathrm{MPa}$ ) conditions. The spatial distribution of longitudinal expansion rate is obtained from the derivative of displacement velocity with respect to position. Regions I to 4, as described in the text, are indicated. Reproduced from Sharp et al. (2004) with permission from Oxford University Press.

region 3 as these are both regions of growth deceleration. Genes differentially expressed in both C2 and C2/3 are more likely to cause growth inhibition at low $\Psi_{\mathrm{w}}$ and are not likely to be part of the maturation program itself, whereas genes differentially expressed only in C2 are more likely related to maturation.

An overall view of expression was created for the three comparisons (Figure 2). Using as cutoff the false discovery rate-adjusted P-value of 0.05, 685 differentially expressed transcripts were identified. These represented 678 different ESTs, tentative contigs, or genomic sequences, as indicated in the gal file for the array. The transcripts were divided into either up-regulated (455) or down-regulated (221) categories except for two that changed category between comparisons. The number of affected transcripts was larger in C2 (420) than in C1 (143) (Figure 2), confirming earlier observations based on EST libraries made from these tissues [7]. Comparison of C1 and C2 shows that only a small minority of differentially expressed tran- scripts were in common: 34 up- and six down-regulated, totaling $7.5 \%$ of the 521 transcripts in the two regions. Thus, the response to water stress depended strongly on position within the root elongation zone. There was also only a small overlap between C2 and C2/3: 60 and 16 transcripts were in common between the 386 up- and the 196 down-regulated, respectively. Given our presupposition that only those genes differentially expressed in both $\mathrm{C} 2$ and $\mathrm{C} 2 / 3$ are associated specifically with the stress response of region 2 , the majority of stress-responsive gene expression was in region 1 , the region that adapts to maintain elongation. Accordingly, the majority of differentially expressed transcripts identified in C2 were likely to be involved in root maturation and not specifically in the water stress response: $75 \%$ (237/317) of the up-regulated and $80 \%$ (81/101) of the down-regulated. Only 16 transcripts were differentially expressed in all three comparisons, underscoring the fact that the response to low $\Psi_{\mathrm{w}}$ was largely region specific and not dominated by genes that are globally induced by water stress. Real time PCR 


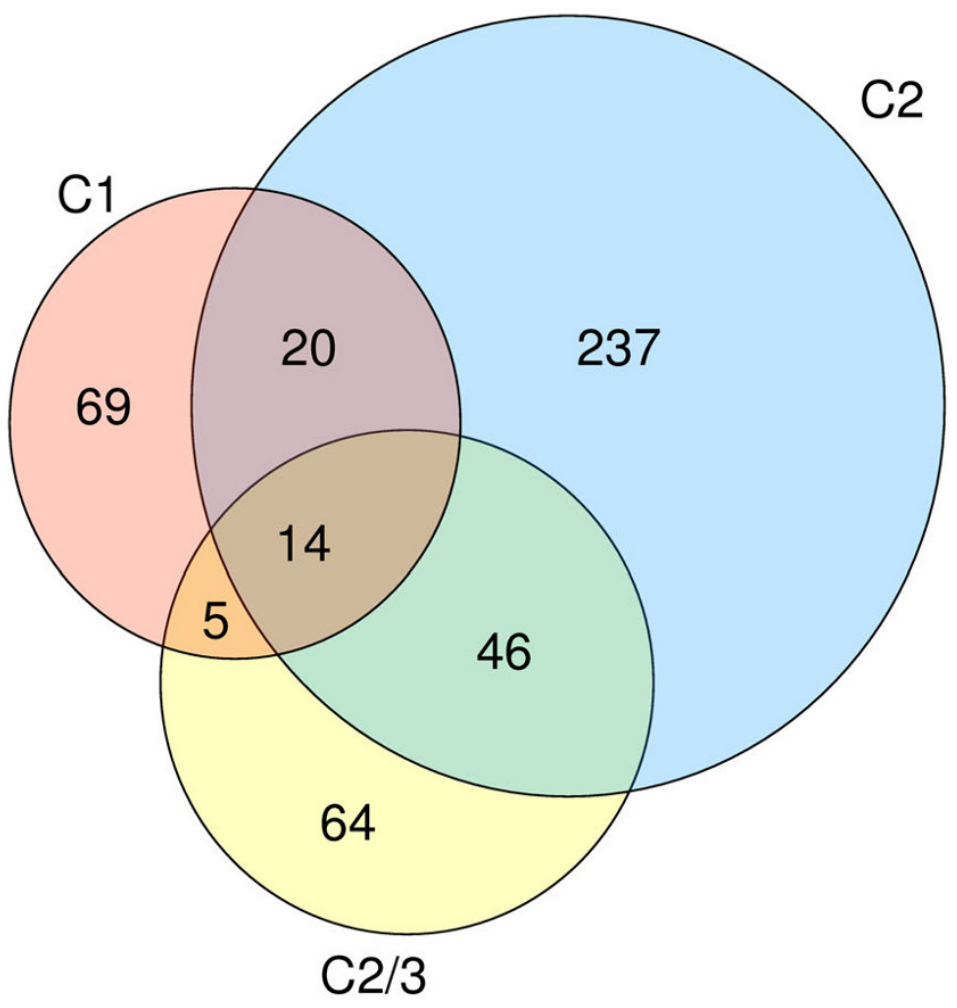

$\underline{\text { Up-regulated }}$

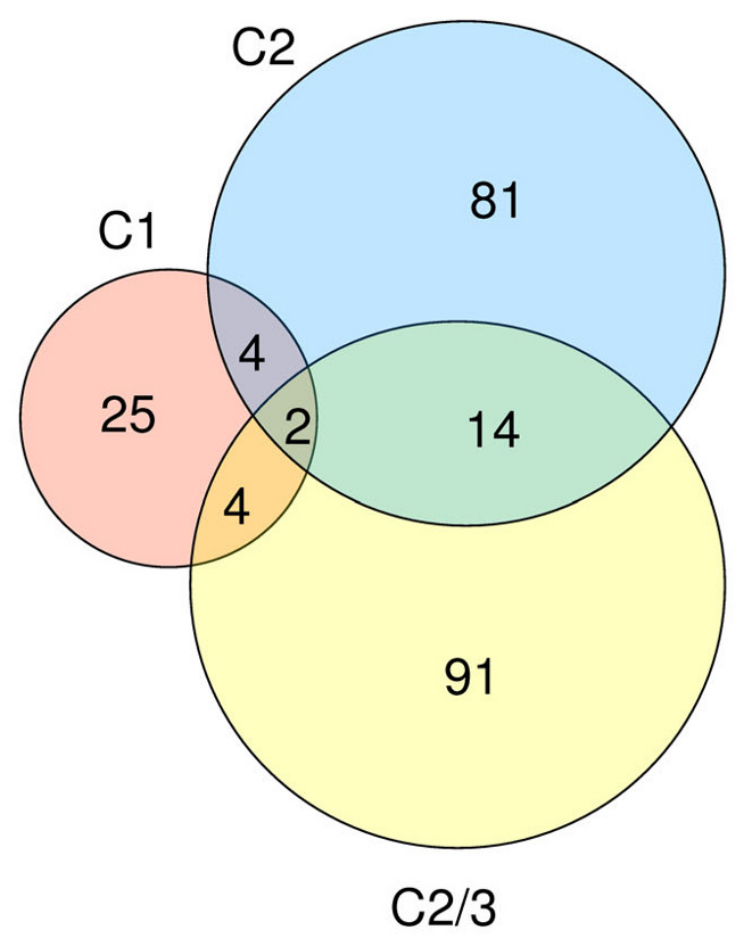

Down-regulated

Figure 2

Venn diagrams illustrating numbers of transcripts up- or down-regulated by water-stress in the three comparisons. $\mathrm{Cl}$ refers to the region I comparison, $\mathrm{C} 2$ to the region 2 comparison, and $\mathrm{C} 2 / 3$ to the comparison of region 2 of water-stressed roots with region 3 of well-watered roots. All but two transcripts are accounted for in this figure; the other two were up-regulated in one region but down-regulated in another. The three comparisons did not share many of the same differentially expressed transcripts, indicating large differences in the response to water stress between the regions.

measurements confirmed the microarray results for all of 17 transcripts studied in region 1 and 22 transcripts studied in region 2 (Figure 3 ).

Transcripts were divided into three groups according to their expression profiles across the three comparisons. The first group includes those transcripts that might have a primary role in the response of root growth to water stress. Since elongation rates in region 1 were similar in well-watered and water-stressed roots, any differentially expressed transcripts in $\mathrm{C} 1$ could have a role in stress adaptation and were placed in the first group regardless of their response in $\mathrm{C} 2$ or $\mathrm{C} 2 / 3$. Transcripts differentially expressed in both $\mathrm{C} 2$ and $\mathrm{C} 2 / 3$ were also placed in this group. The second group includes those transcripts differentially expressed in $\mathrm{C} 2$ alone, which, as explained above, are thought to be part of the root cell maturation program.
The third group includes those transcripts whose expression changed only in $\mathrm{C} 2 / 3$ and these were not considered further. While they may be involved in stress response more experiments are needed to interpret their role.

At least 474 of the 678 differentially-expressed transcripts could be annotated and placed into functional categories (Additional file 1). The distribution of expression patterns across functional categories is given in Additional file 2. Of the functional categories identified for transcripts thought to be part of the primary stress response, reactive oxygen species (ROS) metabolism was the largest with 17 transcripts. This was followed by carbon metabolism (16), nitrogen metabolism (12), signaling molecules (12), membrane transport (11), transcription factors (10), and wall-loosening (6) (Figure 4, Additional file 2). In each functional category these transcripts were more 


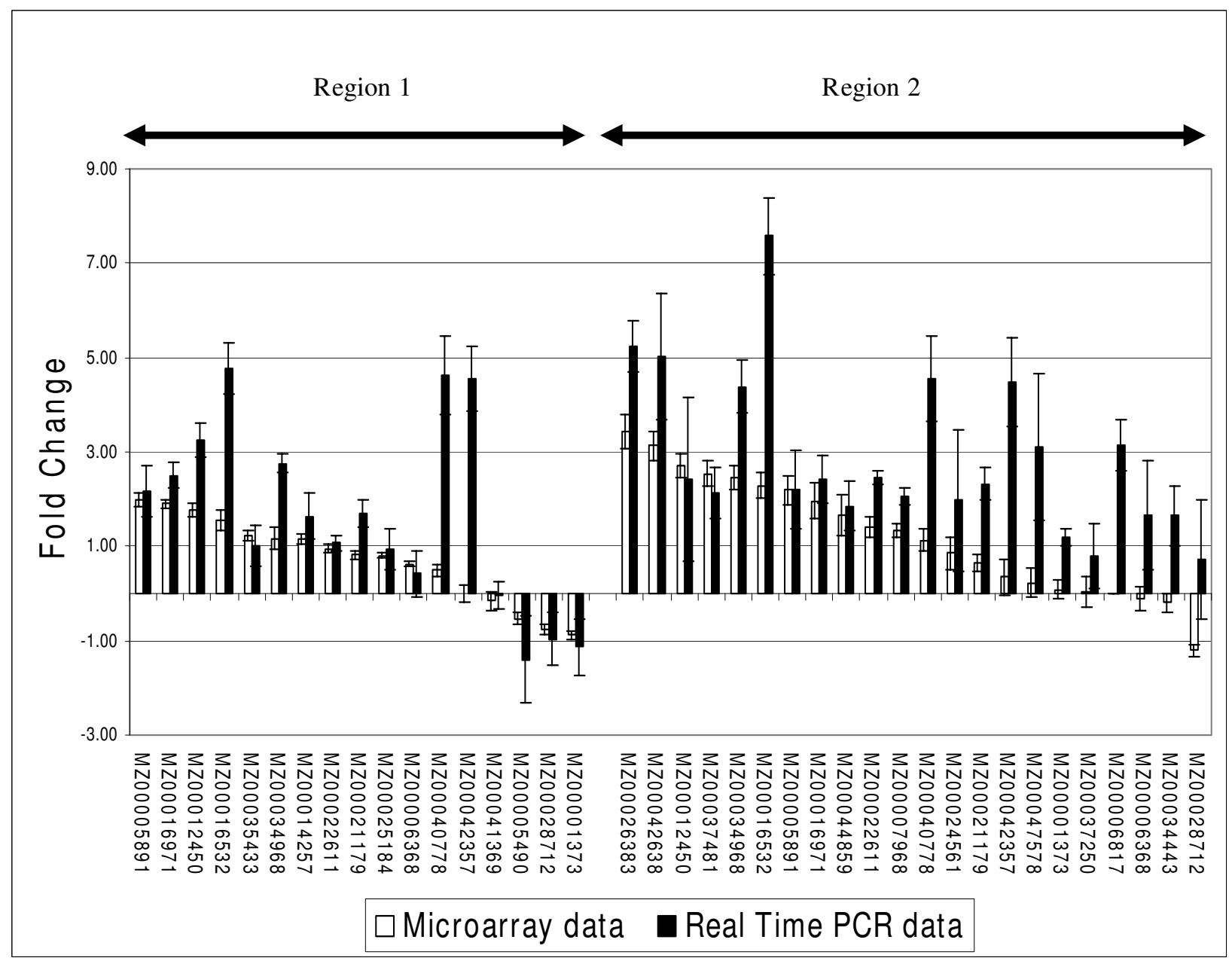

Figure 3

Comparison of real time PCR results with those of the microarray.

often up- rather than down-regulated in water-stressed compared to well-watered roots.

Most differentially expressed transcripts (318) were found in $\mathrm{C} 2$ alone and hence are presumed to be involved in the maturation program (Figure 2, Figure 4, Additional files 1 and 2). Membrane transport (25 transcripts) was the functional category with the greatest number and all of these were up-regulated in C2 (Additional file 2). This was followed by signaling molecules (22), transcription factors (16), other DNA-binding proteins (16), carbon metabolism (14), and lipid metabolism (14) (Additional file 2). In each functional category in the maturation program, transcripts were more often up- rather than down-regulated under water stress.
The genes identified here have little in common with those found in an earlier study by Bassani et al. [11] of differentially-expressed genes in different regions of the maize primary root tip under water stress. Only four of the genes found by Bassani et al. had any similarity (evalue < $\mathrm{e}-10$ ) to transcripts responding in either C1 or C2. The differences in the two studies may be due to growth conditions; Bassani et al. grew plants in the light and imposed a $\Psi_{\mathrm{w}}$ of $-0.5 \mathrm{MPa}$ whereas plants were grown in the dark at $-1.6 \mathrm{MPa}$ in our study. Also, Bassani et al. imposed low $\Psi_{\mathrm{w}}$ using a solution of polyethylene glycol (PEG) which is known to inhibit root growth by limiting oxygen supply in addition to the effects of low $\Psi_{\mathrm{w}}[12]$.

Differential expression in response to water deficit of a limited set of genes in seminal, lateral, and adventitious root tips was studied in rice by Yang et al. $[13,14]$. While 

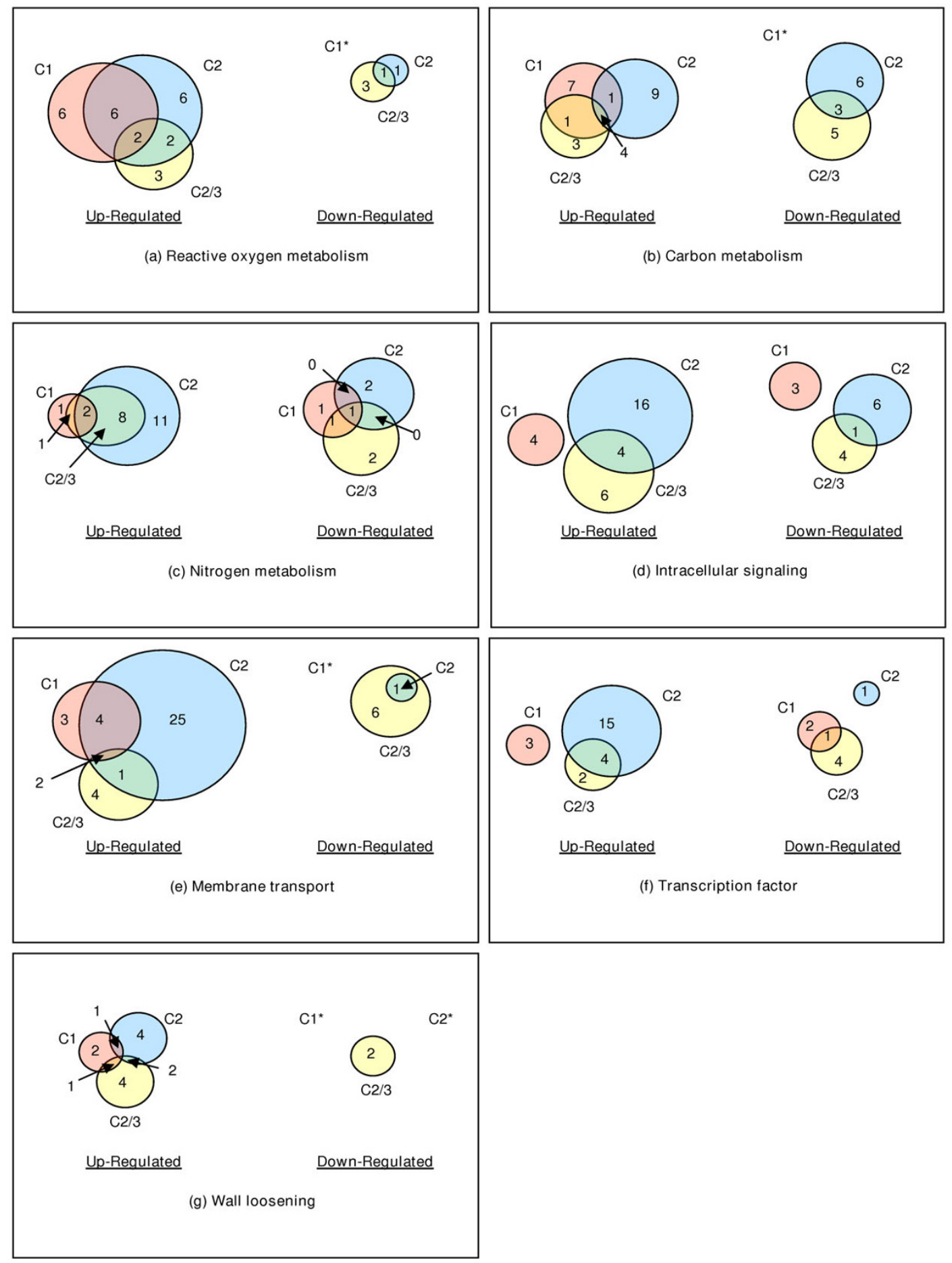

\section{Figure 4}

Regional distribution of expression patterns of water stress-responsive transcripts within specific functional categories. (a) reactive oxygen species metabolism; (b) carbon metabolism; (c) nitrogen metabolism; (d) intracellular signaling; (e) membrane transport; ( $f$ transcription factors; (g) wall loosening. $\mathrm{Cl}$ refers to the region I comparison, $\mathrm{C} 2$ to the region 2 comparison, and $\mathrm{C} 2 / 3$ to the comparison of region 2 of water-stressed roots with region 3 of well-watered roots. *Denotes regions in which there were no responsive genes in that functional category. 
many of their reported genes had similar function to genes in our study none were orthologous to our gene set. Analysis of gene expression in individual tissues has been performed previously [15] in three longitudinal sections from the apex of well-watered Arabidopsis roots that correspond approximately to the three segments we describe here. Tentative Arabidopsis orthologs (defined in the Methods) to our gene set are reported in Additional file 3 .

In what follows selected transcripts from the group of primary stress response genes are first discussed by functional category, followed by consideration of the maturation-related genes, in order to relate their functions to known biochemical and physiological responses to water stress in the maize root tip.

\section{ROS metabolism}

ROS are reactive molecules that can accumulate to toxic levels with water deficit and other stresses. Enzymes that metabolize ROS are therefore important in preventing the damage that excess ROS could cause. Several transcripts for proteins that consume intracellular ROS were up-regulated. A catalase 3 transcript was up-regulated in all three comparisons (MZ00042638) whereas another (MZ00041427) was up-regulated in C1 and C2, confirming results using rtPCR [7], and indicating a need to reduce excess hydrogen peroxide in both regions (Table 1). Several metallothionein-like transcripts were up-regulated in C1 (MZ00039683, MZ00039751, MZ00039699) or in both C1 and C2 (MZ00037083, MZ00013363, MZ00036098). Metallothioneins possess superoxide-and hydroxyl radical-scavenging activities [16]. Thus, at least 11 transcripts were up-regulated whose proteins can decrease peroxide content of the cell interior.

Some amount of ROS production may be required for growth, however. For example, apoplastic ROS [17] and the enzymes that produce them [e.g., $[18,19]]$ have been implicated in growth control via cell wall loosening. Increased abundances of oxalate oxidase and peroxidase proteins, and increased levels of ROS, have been detected in the apoplast of region 1 of the maize primary root under water-stressed conditions [20]. The increased expression by water stress of putative oxalate oxidase transcripts (MZ00026815) in C1 and C2 may thus be involved in regulation of cell expansion. Enhanced apoplastic peroxide content was reported in transgenic maize over-expressing a wheat oxalate oxidase [21], although how the transgene affected growth in the root tip was not described. Over-expression of class III peroxidases in rice caused increased elongation of the root and root cortical cells presumably by generating peroxide [19]. It is unknown whether the up-regulated transcripts for class III peroxidases in C1 (MZ00037273) and in C2 and C2/3 (MZ00015469) also stimulate growth.

\section{Carbon metabolism}

Control of carbohydrate flow to the root tip is determined in part by the sucrose-hydrolyzing enzymes invertase and sucrose synthase. Two distinct invertase transcripts (MZ00005490, MZ00018306) were down-regulated in C2 whereas a sucrose synthase 3 (SUSY3) transcript (MZ00026383) was up-regulated in C1 and C2. Another SUSY3 transcript (MZ00040720) was also up-regulated in C2. SUSY3 was discovered in maize kernels deficient in the two other known sucrose synthases (SH1 and SUS1) [22], and this is the first indication of a role for this gene outside of the kernel and in a stress response. An advantage in ATP consumption, phosphorous use efficiency, and in the creation of sink strength is provided by employing sucrose synthase over invertase in sucrose metabolism [23].

Glucose-1-phosphate (G1P) is a product of SUSY3 and is a substrate for ADP-glucose pyrophosphorylase (ADGase), the first committed step in starch synthesis. Transcripts for the large subunit of ADGase (MZ00014257) and for a putative starch synthase (MZ00021179) were both up-regulated in C1 alone, suggesting increased starch synthesis which might promote carbon flow to the root tip. The tentatively orthologous

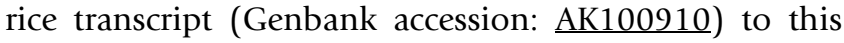
ADGase increased expression in response to the combination of ABA and sugar [24]. ABA also can greatly enhance the induction by sugar of the large subunit of ADGase in Arabidopsis [25]. Birnbaum et al. [15] reported that the tentative Arabidopsis ortholog is most expressed in all tissues studied nearest the apex of the root (Additional file $3)$.

Transcripts coding for two activities that regulate inositol contents were differentially expressed in both $\mathrm{C} 1$ and $\mathrm{C} 2$. Transcripts for $m y o$-inositol-1-phosphate synthase (MIPS) (MZ00041252, MZ00038878), which synthesizes myoinositol, was up-regulated in C1 exclusively whereas transcripts for myo-inositol oxygenase (MZ00015192, MZ00015195), which catabolizes myo-inositol, were down-regulated in $\mathrm{C} 2$ and in $\mathrm{C} 2 / 3$. Taken together, these results suggest a stress-induced increase in myo-inositol content which could be used for (1) conjugation of auxin, (2) as a compatible solute by itself or as a methyl ether, (3) in membrane lipid synthesis, (4) in raffinose synthesis, (5) in UDP-sugar synthesis, and (6) in phytate and phosphoinositide synthesis [26].

\section{Nitrogen metabolism}

Transcripts for a putative $\delta$-1-pyrroline-5-carboxylate (P5C) synthetase (e.g., MZ00025596), which catalyzes the rate-limiting step in proline synthesis, were up-regulated in all three comparisons (Table 1). Transcripts for a putative proline oxidase (e.g., MZ00027872) were down- 
Table I: Selected transcripts involved in ROS metabolism, carbohydrate and proline metabolism, hormone synthesis and hormone response, cell wall loosening proteins, and transport.

\begin{tabular}{|c|c|c|c|c|c|c|}
\hline ID & Cl & $\mathbf{C 2}$ & $\mathrm{C} 2 / 3$ & Annotation & Accession ID & Evalue \\
\hline & \multicolumn{3}{|c|}{ Fold Change } & Reactive Oxygen Metabolism & & \\
\hline MZ00042638 & 3.8 & 8.8 & 5.0 & catalase isozyme 3 (EC I.II.I.6) & gb|AAA3344I.I & 0 \\
\hline MZ0004|427 & 2.7 & 4.0 & & Catalase isozyme 3 & $\mathrm{sp}|\mathrm{PI}| 8 \mid 23$ & $4 \mathrm{E}-100$ \\
\hline MZ00039683 & 2.3 & & & metallothionein-like protein [Saccharum hybrid cultivar] & gb|AAV50043.1 & $2 \mathrm{E}-2 \mathrm{I}$ \\
\hline MZ00037083 & 2.8 & 12.9 & & metallothionein- like protein [Zea mays] & emb|CAA57676.I & $4 \mathrm{E}-33$ \\
\hline MZ000268I5 & 8.9 & 3.0 & & putative oxalate oxidase [Oryza sativa (japonica cultivar-group)] & ref|XP_469352.I & 0 \\
\hline MZ00037273 & 2.0 & & & peroxidase prxI5 precursor [Spinacia oleracea] & $\mathrm{gb} \mid \mathrm{AAF} 63027 . \mathrm{I}$ & $3 \mathrm{E}-55$ \\
\hline \multirow[t]{2}{*}{ MZ000I5469 } & & 27.2 & 4.7 & putative peroxidase [Oryza sativa (japonica cultivar-group)] & ref|NP_919535.I & 0 \\
\hline & & & & Carbon Metabolism & & \\
\hline MZ00026383 & 2.9 & 10.8 & 3.9 & sucrose synthase 3 ZZea mays; $\}$ & $\mathrm{gb} \mid \underline{\mathrm{AAM}} 89473.1$ & 0 \\
\hline MZ000I8306 & & 0.3 & & putative alkaline/neutral invertase \{Oryza sativa (japonica cultivar-group); $\}$ & gb|BAD33266.1 & $2 \mathrm{E}-\mathrm{I} 58$ \\
\hline MZ00005490 & & 0.2 & 0.2 & Beta-fructofuranosidase I precursor (EC 3.2.1.26) \{Zea mays; $\}$ & sp|P49175 & IE-46 \\
\hline MZ000I 4257 & 2.2 & & & Glucose-I-phosphate adenylyltransferase large subunit 2 (EC 2.7.7.27) & sp|P55234 & IE-264 \\
\hline MZ0002II79 & 1.8 & & & Putative starch synthase $\{$ Oryza sativa (japonica cultivar-group);\} & gb|AAK98690.I & $8 \mathrm{E}-17$ \\
\hline MZ0004I252 & 2.2 & & & myo-inositol I-phosphate synthase $\{$ Zea mays; $\}$ & $\mathrm{gb} \mid \mathrm{AAG} 40328.1$ & $8 \mathrm{E}-27 \mathrm{I}$ \\
\hline MZ000I5I92 & & 0.1 & 0.1 & putative myo-inositol oxygenase \{Oryza sativa (japonica cultivar-group);\} & gb|BAD5382I.I & $5 \mathrm{E}-152$ \\
\hline MZ00025596 & 3.5 & 5.2 & 4.0 & putative delta I pyrroline-5-carboxylate synthetase $\{$ Oryza sativa\} & $\mathrm{gb} \mid \mathrm{BAB} 64280.1$ & $8 \mathrm{E}-209$ \\
\hline \multirow[t]{2}{*}{ MZ00027872 } & 0.2 & 0.1 & 0.1 & putative proline oxidase \{Oryza sativa (japonica cultivar-group);\} & $\mathrm{gb} \mid \mathrm{AAP} 54933.1$ & $3 \mathrm{E}-150$ \\
\hline & & & & Hormones & & \\
\hline MZ0005I675 & 0.5 & & & CIPK-like protein \{Oryza sativa (japonica cultivar-group);\} & gb|AAP82I74.1 & $\mathrm{IE}-40$ \\
\hline MZ000I9036 & & 3.0 & 2.2 & putative protein phosphatase $2 C$ \{Oryza sativa (japonica cultivar-group); $\}$ & $\mathrm{gb} \mid \mathrm{AAT} 58680.1$ & $3 \mathrm{E}-155$ \\
\hline MZ00028000 & & 3.6 & & putative protein phosphatase $2 \mathrm{C}$ \{Oryza sativa (japonica cultivar-group);\} & gb|AAT58680.1 & $2 \mathrm{E}-87$ \\
\hline$M Z 00016125$ & & 3.0 & 3.1 & protein phosphatase 2 C-like protein $\{$ Oryza sativa (japonica cultivar-group); $\}$ & $\mathrm{gb} \mid \mathrm{BAC} 05575.1$ & $2 \mathrm{E}-162$ \\
\hline MZ00007968 & & 2.5 & 2.5 & TRABI [Oryza sativa (japonica cultivar-group)] & ref|XP_482899.I & $3 \mathrm{E}-17$ \\
\hline MZ0005I037 & 1.6 & & & ABF3 (ABSCISIC ACID RESPONSIVE ELEMENTS-BINDING FACTOR 3) & ref|NP_567949.I & $3 \mathrm{E}-14$ \\
\hline MZ00026642 & 4.2 & & 6.1 & dehydrin [Zea mays] & $\mathrm{gb} \mid \underline{\mathrm{AAA} 33480.1}$ & 0 \\
\hline MZ0004I440 & & 5.2 & & dehydrin [Zea mays] & gb|AAA33480.I & 0 \\
\hline MZ00042357a & 4.5 & 4.5 & & Group 3 Lea protein MGL3 [Zea mays] & emb|CAA82632.I & $3 \mathrm{E}-76$ \\
\hline MZ000I5996 & 1.2 & & & putative Ubiquitin ligase SINATT5 [Oryza sativa (japonica cultivar-group)] & ref|XP_465055.I & 0 \\
\hline MZ00035785 & 1.8 & & & jacalin homolog [Oryza sativa (japonica cultivar-group)] & $g b \mid \underline{A B A 97248.1}$ & $2 \mathrm{E}-15$ \\
\hline MZ00024083 & 12.4 & & & JI23_HORVU 23 kDa jasmonate-induced protein & sp|P32024 & $2 \mathrm{E}-2 \mathrm{I}$ \\
\hline \multirow[t]{2}{*}{ MZ0005007I } & 0.5 & & & ethylene-binding protein-like [Oryza sativa (japonica cultivar-group)] & dbj|BAD3837I.I & $2 \mathrm{E}-64$ \\
\hline & & & & Wall Loosening & & \\
\hline MZ0002I464 & & 2.2 & & putative endoxyloglucan transferase [Oryza sativa] & ref|NP_922874.I & $2 \mathrm{E}-77$ \\
\hline MZ000I697I & 3.7 & & & alpha-expansin I [Zea mays] & $\mathrm{gb} \mid \underline{\mathrm{AAK} 56119.1}$ & 0 \\
\hline MZ00030567 & 2.4 & & & alpha-expansin [Oryza sativa (japonica cultivar-group)] & ref|XP_4754|8.I & 0 \\
\hline MZ0002930I & & 8.0 & 6.3 & beta-expansin [Oryza sativa] & gb|AAF72988.I & 0 \\
\hline \multirow[t]{2}{*}{ MZ00036823 } & 1.9 & & 1.9 & putative endo- I,3; I,4-beta-D-glucanase [Oryza sativa (japonica cultivar-group)] & gb|AAUI0802.1 & $8 \mathrm{E}-17$ \\
\hline & & & & Transport & & \\
\hline MZO0002500I & 4.6 & 12.1 & 5.7 & Putative anion transporter [Oryza sativa] & ref|XP_470223.I & 0 \\
\hline MZ000068I7 & 3.0 & & & putative ripening regulated protein [Oryza sativa (japonica cultivar-group)] & dbj|BAD46507.I & 7E-36 \\
\hline MZO00II 1868 & 2.2 & & & putative transmembrane protein [Oryza sativa (japonica cultivar-group)] & ref|NP_920876.I & $2 \mathrm{E}-22$ \\
\hline$M Z 000 I 2450$ & 3.4 & 6.5 & & putative amino acid transport protein [Oryza sativa (japonica cultivar-group)] & ref|XP_463772.I & $3 \mathrm{E}-56$ \\
\hline MZ00043256 & 1.5 & 6.5 & & sorbitol transporter [Malus $\times$ domestica] & dbj|BAD42344.I & IE-29 \\
\hline MZ00031622 & 1.5 & & & oligopeptide transporter OPT-like [Oryza sativa (japonica cultivar-group)] & ref|XP_466910.1 & IE-80 \\
\hline MZ0000I869 & & 0.4 & 0.5 & putative organic cation transporter [Oryza sativa (japonica cultivar-group)] & ref|XP_4787|8.I & 0 \\
\hline
\end{tabular}

Legend. $\mathrm{Cl}$ refers to the region I comparison, $\mathrm{C} 2$ to the region 2 comparison, and $\mathrm{C} 2 / 3$ to the comparison of region 2 of water-stressed roots with region 3 of well-watered roots.

regulated in all three comparisons (Table 1). Since altered metabolism in the root tip was not the main cause of proline accumulation with water stress [27], these changes in expression likely act only to supplement the proline pool.

\section{Hormones}

The accumulation of high concentrations of $\mathrm{ABA}$ is required for the maintenance of elongation in waterstressed maize roots [28-30], although these same high 
concentrations of ABA inhibit root growth at high $\Psi_{\mathrm{w}}$ $[30,31]$. Thus, the growth-inhibiting ability of ABA must be diminished at low $\Psi_{\mathrm{w}}$ while permitting the growthmaintaining functions of ABA to operate. Accordingly, we hypothesized that some components of the ABA response are attenuated by stress while others are not.

Transcripts differentially expressed at low $\Psi_{\mathrm{w}}$ which may be part of the mechanism of ABA action in maize root tips fell into three categories: (a) protein kinases, (b) protein phosphatase type 2C (PP2C) proteins, and (c) transcription factors.

(a) A transcript (MZ00051675) for a CIPK3-like protein was down-regulated by stress in $\mathrm{C} 1$ alone (Table 1). CIPK3 is a ser/thr protein kinase involved with calcium sensing in the ABA- and stress- responses of Arabidopsis [32], suggesting this part of the ABA-signaling pathway might be suppressed in maize roots growing at low $\Psi_{\mathrm{w}}$.

(b) Three transcripts for protein phosphatase-like proteins known to restrict ABA response in Arabidopsis roots and other tissues were up-regulated in C2 (ABI1-like; MZ00028000) or also in C2/3 (PP2C-HAB1, MZ00019036; PP2C-HAB2, MZ00016125) (Table 1). In Arabidopsis, PP2C-HAB1 [33], PP2C-HAB2 [34], and $\mathrm{ABI}$ [ [35] each act as negative regulators of $\mathrm{ABA}$ response, and so perhaps attenuate root response to $\mathrm{ABA}$ under water stress.

(c) Two transcripts for bZIP family transcription factors were up-regulated by stress. The first (MZ00007968) represents TRAB1, a transcription factor that interacts with the OSVP1 protein to induce gene expression in rice [36], which increased in $\mathrm{C} 2$ and in $\mathrm{C} 2 / 3$. Rice TRAB1 is expressed in roots and is inducible by ABA [36].

The second transcript is for an Arabidopsis ABA-response element-binding protein (ABF3) (MZ00051037), which exhibited increased expression in C1. Rice plants overexpressing OsDREB1a, a rice homolog of ABF3, displayed retarded growth and increased proline and sugar content when grown under normal conditions. They also demonstrated improved recovery from water deprivation [37].

Some potentially ABA-inducible transcripts were already mentioned. In addition, a maize dehydrin up-regulated in C1 and C2/3 (MZ00026642) and a second up-regulated in $\mathrm{C} 2$ alone (MZ00041440) were tentative orthologs of the rice LIP9 dehydrin. LIP9 was up-regulated in the OsDREB1a over-expressing plants mentioned above [36] and in response to ABA and drought in rice [38]. Dehydrins are expected to help protect cells from stress.
Water-stress can increase auxin levels in maize root tips [8] and exogenous auxin can shorten the elongation zone while promoting growth in the apical region of cereal roots [9]. This suggests that auxin may play a role in root growth at low $\Psi_{\mathrm{w}}$. A transcript (MZ00015996) for a putative SINAT5, a ubiquitin protein ligase, was up-regulated by stress in C1. SINAT5 expression is enhanced by auxin in root tips of Arabidopsis [38] and increased expression of SINAT5 protein in transgenic Arabidopsis promoted root elongation [39]. Thus, the SINAT5-like gene product may act to maintain cell elongation in region 1 of waterstressed maize primary roots.

The up-regulation in $\mathrm{C} 1$ of a transcript similar to a $23-\mathrm{kD}$ jasmonate-induced thionin (MZ00024083) suggests some action of jasmonates due to stress. Thionins are involved in plant defenses to biotic factors [40]. Jasmonates are also able to induce some genes of the jacalin family of lectins which are associated with defense responses. A transcript for a jacalin-like protein was upregulated in C1 (MZ00035785).

In previous studies, some of the response to endogenous ABA in roots at low $\Psi_{\mathrm{w}}$ was attributed to its ability to prevent synthesis of excess ethylene, which otherwise would inhibit root elongation and promote radial swelling [41]. A transcript (MZ00050071) for an ethylene-binding-like protein was down-regulated in $\mathrm{C} 1$. Reduced ability to bind ethylene should make the root less sensitive to ethylene, perhaps influencing root shape. It is noteworthy that maize primary roots are thinner at low compared to high $\Psi_{\mathrm{w}}[4,6]$.

\section{Wall loosening proteins}

The increased wall extensibility in region 1 of waterstressed roots [42] may be due to increased activity of cell wall loosening proteins. Increased activity of xyloglucan endotransglycosylase (XET) was reported in region 1 of water-stressed roots, and was shown to be ABA-dependent [43]. A transcript for XET (MZ00021464) was up-regulated in $\mathrm{C} 2$ (Table 1) but not in $\mathrm{C} 1$ where the enzyme activity increases [43]. This suggests that the increased enzyme activity in region 1 was due to post-transcriptional events.

Expansins are also associated with increased wall-loosening in water-stressed maize root tips [42]. Two transcripts

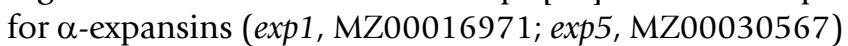
were up-regulated in $\mathrm{C} 1$, while $\beta$-expansins (e.g., $\exp B 3$, MZ00029301) were up-regulated in $C 2$ and $C 2 / 3$. These data confirm previous measures of increased expression of $\alpha$-expansin genes and $\exp B 6$ in stressed maize root tips [44]. It is unclear what role $\beta$-expansins play in the regulation of growth in region 2 at low $\Psi_{w^{\prime}}$ in which elongation was inhibited, as they are able to loosen walls [45]. 
The major hemicellulose class of the maize primary cell wall is composed of mixed linkage $\beta$-glucans which are believed to be cleaved by endo-1,3;1,4-beta-D-glucanases to cause wall loosening [46]. A transcript for a putative endo-1,3;1,4-beta-D-glucanase was up-regulated in $\mathrm{C} 1$, and an endo-1,3;1,4-beta-D-glucanase was identified in the maize primary root elongation zone in a cell wall proteomic study of well-watered roots [47]. More recently, however, a comprehensive study on root region specific cell wall protein profiles showed decreased abundance of two endo-1,3;1,4-beta-D-glucanases in region 1 under water deficit conditions [20]. These observations suggest that changes at the transcript level for this particular member may not be reflected at the translational level, or that members of this gene family may have different subcellular localizations [48].

\section{Membrane transport}

Ober and Sharp [49] reported that maize root tip cortical cell membranes are hyperpolarized by stress and that the hyperpolarization requires increased $\mathrm{H}^{+}$-ATPase activity of the plasma membrane. Potassium and chloride ions are also important for the hyperpolarization. When ABA is prevented from accumulating the membrane becomes more hyperpolarized in the apical 2- to 3-mm, suggesting that $\mathrm{ABA}$ acts on ion transport or transporters in the regulation of growth. We hypothesized that changes in expression of genes for such transporters occur in this region. Two putative anion transporters were up-regulated in all three comparisons (MZ00025001, MZ00043643) and a third in C1 and C2 (MZ00009288) which might serve this function (Table 1).

Two transcripts coding for proteins with similarity to MATE efflux family proteins were increased in C1 (MZ00006817, MZ00011868) and a third in both C1 and C2 (MZ00030937). The functions of only a few MATE proteins are known $[50,51]$ although some respond to phosphate- [52] or iron-deficiency [53], conditions which may accompany water stress. A transcript for a putative amino acid transporter (MZ00012450) was up-regulated in $\mathrm{C} 1$ and $\mathrm{C} 2$ as was one for a sugar transport family protein (MZ00043256), possibly in response to enhanced nutritional requirements. A transcript for an oligopeptide transporter-like gene (MZ00031622) was increased in C1, although no functional characterization is available [54].

\section{Root maturation-related genes}

Transcripts were indentified that were presumed to be related to tissue maturation in region 2 of stressed roots and in region 3 of control roots and not directly responsive to water stress. Such genes might function in cell-wall thickening, vascular differentiation, and increased resistance to water and solute transport, among other processes. Some pertinent transcripts are listed in Table 2.
Inositol phosphates such as inositol 1,4,5-triphosphate $\left(\mathrm{IP}_{3}\right)[55]$ and inositol hexakisphosphate ( $\mathrm{IP}_{6}$, or phytate) [56] have roles in intracellular signaling. Inositol 5-phosphatase can decrease content of $\mathrm{IP}_{3}$ and in Arabidopsis it is induced by ABA [57]. Phytase dephosphorylates phytate. Phytate is synthesized in maize roots [58] and phytase mRNA and protein have been localized in the pericycle, endodermis, and rhizodermis of maize root tips [59]. Transcripts for enzymes that could metabolize inositol phosphates, one for inositol 5-phosphatase (MZ00012753) and two for phytase (MZ00034353, MZ00028553), were up-regulated by stress in C2. Little is known about the role of inositol phosphate signaling in root development or its response to water stress.

Poroyko et al. [7] found that transcripts for inorganic ion and water transport and metabolism were generally upregulated in region 2 . We found some 25 transcripts whose functions are related to membrane transport were up-regulated in $\mathrm{C} 2$ alone. Cells in the more mature region of the expanding root tip have decreased symplastic continuity with the phloem [60]. As a consequence solutes and water must traverse more membranes to be taken up by cells. Many of these transporters may be part of that response. For example, it is expected that increased uptake from the apoplast of sugars and amino acids is required, and consistent with this idea several putative sugar and amino acid transporters were up-regulated. The differential regulation of several sulfate transporters was notable since sulfate content increases in the xylem of more mature maize plants of this genotype under water stress conditions [61]. Transcripts for $A B C$ transporters were identified as well, belonging to the EPD family that is not yet well described in plants [62].

Expression increased in $\mathrm{C} 2$ alone for three O-methyl transferase transcripts (MZ00004720, MZ00026069, MZ00025206). These may be involved in creating phenylpropanoid precursors to lignin and suberin whose contents increase in mature roots [63].

Up-regulated transcripts for GA metabolism (MZ00007636, gibberellin 2-oxidase; MZ00018690, gibberellin 20-oxidase) and response (MZ00026517, putative gibberellin regulated protein) were identified in C2. The Arabidopsis tentative ortholog was also most expressed in tissues of this region of the root apex (Additional File $3 ;[15])$. A role for GA in root cell growth was previously indicated by the altered pattern of radial swelling observed in GA-deficient maize seedlings [64].

\section{Promoter analysis}

The regulatory mechanisms of genes are mostly controlled by the binding of transcription factors to the sites located upstream of coding regions. Possible transcription factor 
Table 2: Selected transcripts which are likely to be involved in cell wall maturation regardless of water status.

\begin{tabular}{|c|c|c|c|c|c|}
\hline ID & $\mathbf{C l}$ & $\mathrm{C} 2 / 3$ & Annotation & Accession ID & Evalue \\
\hline & Fold & Change & Root Maturation & & \\
\hline MZ00008104 & & 3.1 & $A B C$ transporter family protein-like $\{$ Oryza sativa (japonica cultivar-group); $\}$ & gb|BAC84400.1 & IE-I3 \\
\hline MZ000I8690 & & 2.4 & gibberellin 20 -oxidase I [Lolium perenne] & gb|AAY67841.I & 0 \\
\hline MZ00007636 & & 2.1 & Gibberellin 2-oxidase [Oryza sativa (japonica cultivar-group)] & ref $\mid X P \_475621.1$ & IE-19 \\
\hline MZ00050533 & & 2.2 & mechanosensitive ion channel domain-containing protein-like $\{$ Oryza\} & $\mathrm{gb} \mid \mathrm{BAD} 28130.1$ & $5 \mathrm{E}-117$ \\
\hline MZ000I658I & & 5.4 & NOD26-like membrane integral protein ZmNIP2-I \{Zea mays; $\}$ & gb|AAK2675I.I & $6 \mathrm{E}-143$ \\
\hline MZ00026069 & & 1.9 & O-methyltransferase $\{$ Secale cereale; $\}$ & gb|AAO23335.1 & $4 \mathrm{E}-\mathrm{I} 14$ \\
\hline MZ00004720 & & 22.9 & O-methyltransferase ZRP4 (EC 2.I.I.-) (OMT). \{Zea mays; $\}$ & sp|P47917 & $7 E-69$ \\
\hline MZ00034353 & & 2.6 & phytase $\{$ Zea mays; $\}$ & gb|CAAII39|.I & IE-199 \\
\hline MZ000265I7 & & 4.0 & putative gibberellin regulated protein [Oryza sativa (japonica cultivar-group)] & gb|AAR87222.I & $4 \mathrm{E}-32$ \\
\hline MZ0004678I & & 3.3 & putative $A B C$ transporter protein $\{$ Arabidopsis thaliana; & gb|AAK92745.I & $2 \mathrm{E}-85$ \\
\hline MZ00049827 & & 2.7 & putative amino acid transport protein \{Oryza sativa (japonica cultivar-group);\} & gb|BAD08181.1 & $2 \mathrm{E}-86$ \\
\hline MZ00044334 & & 3.3 & putative amino acid transporter \{Oryza sativa (japonica cultivar-group);\} & gb|AAV24773.I & $2 \mathrm{E}-149$ \\
\hline MZ000I 2753 & & 5.0 & putative inositol polyphosphate 5-phosphatase [Oryza sativa] & ref|XP_550422.I & $3 \mathrm{E}-47$ \\
\hline MZ0004I660 & & 7.0 & putative MATE efflux family protein \{Oryza sativa (japonica cultivar-group);\} & gb|AASOI970.1 & $2 \mathrm{E}-74$ \\
\hline MZ00019635 & & 3.9 & $\begin{array}{l}\text { putative multidrug resistance } \mathrm{p} \text {-glycoprotein \{Oryza sativa (japonica cultivar- } \\
\text { group); }\end{array}$ & $\mathrm{gb}|\mathrm{BAD}| 6475.1$ & $4 \mathrm{E}-66$ \\
\hline MZ000I948I & & 4.4 & putative nitrite transporter \{Oryza sativa (japonica cultivar-group);\} & gb|BAD54372.1 & IE-20 \\
\hline MZ00025206 & & 8.2 & putative o-methyltransferase ZRP4 \{Oryza sativa (japonica cultivar-group);\} & gb|AAP51889.1 & 7E-72 \\
\hline MZO00005402 & & 1.8 & putative PDR-like ABC transporter \{Oryza sativa (japonica cultivar-group); & gb|BAD53546.I & $2 \mathrm{E}-74$ \\
\hline MZ00028553 & & 2.9 & putative phytase $\{$ Oryza sativa (japonica cultivar-group);\} & gb|AAO73273.1 & IE-248 \\
\hline MZ00052I25 & & 3.1 & putative proton-dependent oligopeptide transporter (POT) \{Oryza\} & gb|AAT85250.1 & $4 \mathrm{E}-120$ \\
\hline MZ00048363 & & 2.3 & putative sialin \{Oryza sativa (japonica cultivar-group);\} & gb|BAD46232.1 & $4 \mathrm{E}-87$ \\
\hline$M Z 00021212$ & & 3.2 & putative sugar transporter \{Oryza sativa (japonica cultivar-group);\} & gb|BAD21843.1 & $5 \mathrm{E}-52$ \\
\hline MZ00026965 & & 4.4 & Putative sulfate transporter \{Oryza sativa (japonica cultivar-group);\} & gb|AAN59769.1 & $3 \mathrm{E}-127$ \\
\hline MZ00048706 & & 4.0 & Putative sulfate transporter ATSTI \{Oryza sativa (japonica cultivar-group);\} & gb|AAN0687I.I & $3 \mathrm{E}-102$ \\
\hline MZ00044209 & & 3.2 & putative $\mathrm{Zn}$ and $\mathrm{Cd}$ transporter $\{$ Thlaspi caerulescens; $\}$ & gb|CAC86389.1 & IE-19 \\
\hline MZ0004I46I & & 2.8 & $\begin{array}{l}\text { Triose phosphate/phosphate translocator, chloroplast precursor (CTPT). }\{\text { Zea } \\
\text { mays; }\}\end{array}$ & sp|P49133 & $3 \mathrm{E}-213$ \\
\hline
\end{tabular}

Legend. $\mathrm{Cl}$ refers to the region I comparison, $\mathrm{C} 2$ to the region 2 comparison, and $\mathrm{C} 2 / 3$ to the comparison of region 2 of water-stressed roots with region 3 of well-watered roots.

binding sites (cis elements) of the differentially expressed genes found in this study were sought. Promoter regions were defined as the 1,000 bases upstream of the coding regions of full sequence gene models for maize (available from The TIGR Maize Database), or for tentatively orthologous rice and Arabidopsis genes. Cis elements were identified in the promoters of 167 maize genes or their tentative orthologs using the PLACE database. While 61 classes of cis elements were detected (Additional file 4) there was little difference in their distribution between sequences that belonged to the primary or maturation classes of transcripts, and hierarchical clustering techniques did not reveal any associations with specific expression patterns (not shown).

\section{Conclusion}

We explored gene expression in the maize primary root to identify causes for the changes observed in the spatial pattern of root elongation at low $\Psi_{\mathrm{w}}$. The two regions of the root studied showed distinctly different transcript profiles underscoring the importance of spatial analysis. Within region 1, where longitudinal expansion rate is maintained during stress, all differentially expressed transcripts were considered to be part of the mechanism of adaptation to stress. Within region 2 , the region where longitudinal expansion decreases from the maximal control rate to a progressively slower rate under stress, transcripts were divided into two groups: those that were part of the stress response that brought about early root cell maturation, and those that were part of maturation itself. Region 1 contained a greater number of differentially expressed genes involved in the stress response than did region 2, even though region 2 had the greater total number of differentially expressed genes. This result was expected given the maintenance of elongation in region 1 and its inhibition in region 2 of water-stressed roots.

Our results support and add molecular details to the model of root growth maintenance under stress via increased wall loosening in region 1, osmotic adjustment, regulation by $\mathrm{ABA}$, and changes in membrane transport. The data suggest a need for control of intracellular ROS content by catalase and metallothioneins and for apoplastic hydrogen peroxide production by oxalate oxidase and 
other cell wall proteins to cause wall loosening. A transcript with similarity to a mixed linkage $\beta$-glucanase suggests a role for this enzyme in stress adaptation in the root growth zone. Carbohydrate metabolism appears altered at the transcript level to involve roles for SUSY3 and enhanced starch synthesis. The mechanism of osmotic adjustment by proline accumulation was extended to include changes in expression of genes for proline metabolism. Altered expression of transcripts similar to known members of the ABA signaling pathway suggest some parts of the ABA response network are attenuated while others are not, which may explain how the stressed root tolerates, and requires, high endogenous levels of this hormone. The stress-enhanced expression of a SINAT5like transcript may link auxin to growth maintenance in region 1. Change in an ethylene-binding like protein is suggested to help control the shape of the stressed root. Evidence for jasmonate-induced gene expression was also indicated that is probably related to biotic stress defense. The up-regulated transcripts for membrane anion transport may bring about the known stress-induced changes in membrane potential. Together the data show that the regulation of root growth at low water potentials involves region-specific changes in many different aspects of cell metabolism, signaling, and transport.

\section{Methods}

\section{Maize seedling culture and root harvest}

Maize (Zea mays L. cv FR697) seeds were imbibed for $24 \mathrm{~h}$ in $1 \mathrm{mM} \mathrm{CaSO}_{4}$. Seeds were then germinated for $28 \mathrm{~h}$ in vermiculite well-moistened with $1 \mathrm{mM} \mathrm{CaSO}_{4}$ at $29^{\circ} \mathrm{C}$ in the dark [41]. Seedlings with primary roots $12-20 \mathrm{~mm}$ in length were transplanted into vermiculite mixed with predetermined amounts of $1 \mathrm{mM} \mathrm{CaSO}_{4}$ to create high (-0.03 $\mathrm{MPa})$ or low (-1.6 MPa) $\Psi_{\mathrm{w}}$ and grown under near-saturating humidity conditions to prevent further drying of the media. Vermiculite $\Psi_{\mathrm{w}}$ was measured by isopiestic thermocouple psychrometry [65].

By combining harvests from a series of experiments, four biological replicates of 440 pooled well-watered and 660 pooled water-stressed primary roots were collected at $48 \mathrm{~h}$ after transplanting (using a green safelight; [29]). The apical $12 \mathrm{~mm}$ of each root was sectioned into three regions based on previously-characterized longitudinal expansion rate profiles (Figure 1; distances are from the junction of the root apex and root cap): region $1,0-3 \mathrm{~mm}$ plus the root cap; region 2, 3-7 mm; region 3, 7-12 mm. Samples were collected by position and immediately frozen in liquid nitrogen.

\section{RNA isolation}

Total RNA was isolated from maize root apical segments using Trizol reagent following the manufacturer's instructions (Invitrogen Corp., Carlsbad, CA). Residual DNA was removed by Dnase I (Invitrogen, Carlsbad, CA) treatment for $15 \mathrm{~min}$ at room temperature, followed by use of RNeasy columns (Qiagen, Valencia, CA).

\section{Microarray, hybridization, and data analysis}

Gene expression changes were assessed using pair-wise comparisons of water-stressed region 1 with well-watered region 1 (designated C1), water-stressed region 2 with well-watered region 2 (designated C2), and water-stressed region 2 with well-watered region 3 (designated C2/3). Maize oligonucleotide arrays printed at the University of Arizona were used [66]. Each maize array consisted of two slides that together contained 57,452 unique oligos, mostly 70-mers. The Maize Root Genomics Project [67] contributed 668 novel sequences to the array. Overall, 30,000 genes were represented on the array. Conservative estimates place the maize transcriptome at 59,000 genes ([68]; H Bohnert, unpublished). More details about the array can be found in Gardiner et al., [69]. Additional annotation of the parent sequences to the oligos was performed by blastx search of protein databases (NR) at NCBI [70], UniProt [71], or TAIR [72]. First strand cDNAs were synthesized from $50 \mu \mathrm{g}$ of total RNA using anchored oligo(dT) 24 primers with SuperScript III RT (Invitrogen, Carlsbad, CA), and aminoallyl-dUTP was incorporated into the cDNAs. The RNA template was removed by treatment with RnaseH (Invitrogen, Carlsbad, CA), and cDNAs were purified to remove unincorporated aminoallyl-dUTP using Microcon 30 spin concentrators (Millipore Corp., Bedford, MA). Following purification, monoreactive-Cye 5 or Cye3 dyes (Amersham Biosciences Corp., Piscataway, NJ) were conjugated to aminoallyldUTP on the cDNAs and the unconjugated dye was removed using Qiagen PCR purification columns. The purified Cy3 and Cy5-labeled cDNAs were concentrated to $60 \mu \mathrm{l}$ and hybridized to the maize oligonucleotide array for $16-18 \mathrm{~h}$ at $42^{\circ} \mathrm{C}$. Following hybridization, the arrays were washed three times, twice with medium stringency buffer $(1 \times$ SSC, $0.2 \%$ SDS $)$ and once with high stringency buffer $(0.1 \times$ SSC, $0.2 \%$ SDS $)$. Washed slides were dried and scanned immediately using a GenePix scanner (Gene$\mathrm{Pix}^{\circledast}$ 4000B, Axon Instruments, Inc.) at $532 \mathrm{~nm}(17 \mathrm{~mW})$ and $635 \mathrm{~nm}(10 \mathrm{~mW})$. GenePix Pro 4.1 software was then used to extract spot intensity data.

Each of the three comparisons included 16 slides corresponding to four biological replications of two slides each with dye-swap. The R programming environment, including the limma package, was used to process and statistically analyze the data. Mean foreground intensity values were $\log$ transformed and subjected to lowess normalization to correct for intensity-dependant dye effects. To obtain accurate and precise estimates of gene expression values a mixed linear model was applied which was based 
on a two-step approach essentially as described by Wolfinger et al. [73].

The mixed linear model that was fit across genes is

$$
y_{i j k l g}=\mu+T_{i}+D_{j}+(T D)_{i j}+R_{k}+(A / T D)_{i j l}+(A / R)_{k l}+e_{i j k l g}
$$

where $y_{i j k l g}$ is the log intensity value for the $g^{\text {th }}$ gene with treatment $i$, dye $j$, and replicate $k$ on the $l^{\text {th }}$ array, $\mu$ is the overall mean across all factors, $T_{i}$ is the overall effect of treatment $i, D_{j}$ is the overall effect of dye $j, R_{k}$ is overall effect of replicates, $(T D)_{i j}$ is the interaction of the $i^{\text {th }}$ treatment and $j^{\text {th }}$ dye, $(A / T D)_{i j}$ is the effect of $t^{t h}$ array within $i^{t h}$ treatment and $j^{\text {th }}$ dye, $(A / R)_{k l}$ is the effect of $l^{t h}$ array within $k^{\text {th }}$ replicate, and $e_{i j k l g}$ is the residual error term, i.e. variation that is not explained by the factors included in the model. In the model the treatment and the dye effects were treated as fixed, and the replicate and the array effects within replicate or treatment by dye effect as random. Residuals obtained from the global model were fit, one gene at a time, to the following mixed model:

$$
r_{i j k l g}=\mu+T_{i}+D_{j}+R_{k}+(A / R)_{k l}+e_{i j k l g}
$$

where the effects fit in the model were treated the same as in the global model. False discovery rate (FDR) adjusted $P$-values were determined for 64,870 spots in C1, 56,609 spots in $\mathrm{C} 2$ and in $\mathrm{C} 2 / 3$. The difference in numbers of spots was due to the removal from the second and third sets of all values with saturated intensities. The threshold for the FDR was set at 0.05 , i.e., there is a $5 \%$ chance that the designation of significance is false.

We define as "tentatively orthologous" a sequence from another species if it was the top scoring match in both parts of a reciprocal BLAST analysis pitting the entire set of maize array sequences with all known genes of that species as defined by TAIR (Arabidopsis) or TIGR (rice).

\section{Promoter Analysis}

Promoter regions were deemed to be the 1,000 bases upstream of the coding regions of the maize sequence full gene models available from The TIGR Maize Database (AZM version 5 [74]). Similar promoter sequences were obtained for tentatively orthologous rice genes from TIGR Rice Genome Annotation [75] and Arabidopsis [72]. Motifs listed in the PLACE database [76] were identified in each of the three sets of promoters using the PLACE website. PLACE was constructed and maintained at the National Institute of Agrobiological Sciences (NIAS) and was made available without charge.

\section{Verification of microarray data by gene specific relative quantitative RT-PCR}

To validate the differential expression pattern obtained from the microarray analysis, transcripts from the same RNA samples of well-watered and water-stressed region 1 and region 2 tissues were quantified using real-time PCR. cDNA was synthesized according to the Taqman RT kit protocol (ABI, Foster City, CA). PCR primers were designed using Primer Express 2.0 (Applied Biosystems, $\mathrm{ABI}$ ) to create amplicons of 100 to $150 \mathrm{bp}$. The experiment was performed for three biological replicates using the Zea mays actin gene (gi|21206665) as an endogenous control. The real-time measurements were carried out with the GeneAmp 7000 Sequence Detection System (Applied Biosystem) using the standard protocol.

\section{Authors' contributions}

WGS, WT, BV and KC participated in the design of experiments, microarray hybridization, microarray analysis, qRT-PCR validation of array results, bioinformatic analysis, data interpretation and manuscript preparation. LGH, MEL and JZ conducted the physiology experiments and collected the root tissues. J-JK and DH helped in the statistical analysis of microarray data. HJB, DPS, GED, GKS, RES and HTN participated in the design of experiments, data interpretation and revision of the manuscript. All authors read and approved the final manuscript.

\section{Additional material}

\section{Additional file 1}

List of differentially expressed transcripts by their Operon ids and their relationship to the most similar translation product in NR. Genes are categorized according to primary stress response, maturation related response and functional classification. The parent est sequence identifier, the fold change, the FDR-adjusted p value, and the accession ID, annotation, score, and evalue obtained by BLASTX alignment against the non-redundant protein database at NCBI are given.

Click here for file

[http://www.biomedcentral.com/content/supplementary/14712229-8-32-S1.xls]

\section{Additional file 2}

Functional categories and patterns of differential expression across the three comparisons.

Click here for file

[http://www.biomedcentral.com/content/supplementary/14712229-8-32-S2.xls]

\section{Additional file 3}

Tentatively orthologous Arabidopsis genes and a description of their expression profile from Birnbaum et al. [15]

Click here for file

[http://www.biomedcentral.com/content/supplementary/14712229-8-32-S3.xls] 


\section{Additional file 4}

Distribution of cis elements found in the region up to 1,000 bases upstream of the coding sequences of maize genes identified in this study, or in tentative orthologs of genes identified in this study.

Click here for file

[http://www.biomedcentral.com/content/supplementary/14712229-8-32-S4.xls]

\section{Acknowledgements}

This work was supported by a grant from the National Science Foundation, Plant Genome Program (Grant no. DBI-021 1842).

\section{References}

I. Boyer JS: Plant productivity and the environment. Science 1982, 21 8:443-448.

2. Sharp RE, Davies WJ: Regulation of growth and development of plants growing with a restricted supply of water. In Plants under stress Edited by: Jones HG, Flowers TL, Jones MB. Cambridge: Cambridge University Press; 1989:7I-93.

3. Spollen WG, Sharp RE, Saab IN, Wu Y: Regulation of cell expansion in roots and shoots at low water potentials. In Water deficits Plant responses from cell to community Edited by: Smith JAC, Griffiths H. Oxford: Bios Scientific Publishers; 1993:37-52.

4. Sharp RE, Silk WK, Hsiao TC: Growth of the maize primary root at low water potentials. I. Spatial distribution of expansive growth. Plant Physiol 1988, 87:50-57.

5. Sharp RE, Poroyko V, Hejlek LG, Spollen WG, Springer GK, Bohnert HJ, Nguyen HT: Root growth maintenance during water deficits: physiology to functional genomics. J Exp Bot 2004, 55:2343-235I.

6. Liang BM, Sharp RE, Baskin TI: Regulation of growth anisotropy in well-watered and water-stressed maize roots. I. Spatial distribution of longitudinal, radial, and tangential expansion rates. Plant Physiol 1997, I I 5:101-11I.

7. Poroyko V, Spollen WG, Hejlek LG, Hernandez AG, LeNoble ME, Davis G, Nguyen HT, Springer GK, Sharp RE, Bohnert HJ: Comparing regional transcript profiles from maize primary roots under well-watered and low water potential conditions. J Exp Bot 2007, 58:279-289.

8. Ribaut JM, Pilet PE: Water stress and indol-3yl-acetic acid content of maize roots. Planta 1994, 193:502-507.

9. Ishikawa $\mathrm{H}$, Evans ML: The role of the distal elongation zone in the response of maize roots to auxin and gravity. Plant Physiol 1993, 102:1203-1210.

10. Fan L, Linker R, Gepstein S, Tanimoto E, Yamamoto R, Neumann PM: Progressive inhibition by water deficit of cell wall extensibility and growth along the elongation zone of maize roots is related to increased lignin metabolism and progressive stelar accumulation of wallphenolics. Plant Physiol 2006, | 40:603-6|2.

II. Bassani M, Neumann PM, Gepstein S: Differential expression profiles of growth-related genes in the elongation zone of maize primary roots. Plant Mol Biol 2004, 56:367-380.

12. Verslues PE, Ober ES, Sharp RE: Root growth and oxygen relations at low water potentials. Impact of oxygen availability in polyethylene glycol solutions. Plant Physiol 1998, I 16:1403-1412.

13. Yang L, Zheng B, Mao C, Qi X, Liu F, Wu P: Analysis of transcripts that are differentially expressed in three sectors of the rice root system under water deficit. Mol Gen Genom 2004, 272:433-442.

14. Yang L, Zheng B, Mao C, Yi K, Liu F, Wu Y, Tao Q, Wu P: cDNAAFLP analysis of inducible gene expression in the rice seminal root tips under a water deficit. Gene 2003, 3 I 4: I4I- I 48.

15. Birnbaum K, Shasha DE, Wang JY, Jung JW, Lambert GM, Galbraith DW, Benfey PN: A gene expression map of the Arabidopsis root. Science 2003, 302:1956-1960.

16. Wong HL, Sakamoto T, Kawasaki T, Umemura K, Shimamoto K: Down-regulation of metallothionein, a reactive oxygen scav- enger, by the small GTPase OsRacl in rice. Plant Physiol 2004, 135:1447-1456.

17. Liszkay A, van der Zalm E, Schopfer P: Production of reactive oxygen intermediates $\left(\mathrm{O}_{2}^{-}, \mathrm{H}_{2} \mathrm{O}_{2}\right.$, and $\left.{ }^{\circ} \mathrm{OH}\right)$ by maize roots and their role in wall loosening and elongation growth. Plant Physiol 2004, I36:3|| 4-3।23.

18. Kawaoka A, Matsunaga E, Endo S, Kondo S, Yoshida K, Shinmyo A, Ebinuma $H$ : Ectopic expression of a horseradish peroxidase enhances growth rate and increases oxidative stress resistance in hybrid aspen. Plant Physiol 2003, I 32: I I77-I I 85.

19. Passardi F, Tognolli M, De Meyer M, Panel C, Dunand C: Two cell wall associated peroxidases from Arabidopsis influence root elongation. Planta 2006, 223:965-974.

20. Zhu J, Alvarez S, Marsh EL, LeNoble ME, Cho I-J, Sivaguru M, Chen S, Nguyen HT, Wu Y, Schachtman DP, Sharp RE: Cell wall proteome in the maize primary root elongation zone. II. Region-specific changes in water soluble and lightly ionically bound proteins under water deficit. Plant Physiol 2007, I 45: I533-I548.

21. Ramputh AI, Arnason JT, Cass L, Simmonds JA: Reduced herbivory of the European corn borer (Ostrinia nubilalis) on corn transformed with germin, a wheat oxalate oxidase gene. Plant $\mathrm{Sci}$ 2002, 162:431-440.

22. Carlson SJ, Chourey PS, Helentjaris T, Datta R: Gene expression studies on developing kernels of maize sucrose synthase (SuSy) mutants show evidence for a third SuSy gene. Plant Mol Biol 2002, 49:15-29.

23. Xu D-P, Sung S-JS, Loboda T, Kormanik PP, Black CC: Characterization of sucrolysis via the uridine diphosphate and pyrophosphate-dependent sucrose synthase pathway. Plant Physiol 1989, 90:635-642.

24. Akihiro T, Mizuno K, Fujimura T: Gene expression of ADP-glucose pyrophosphorylase and starch contents in rice cultured cells are cooperatively regulated by sucrose and ABA. Plant Cell Physiol 2005, 46:937-946.

25. Rook F, Corke F, Card R, Munz G, Smith C, Bevan MW: Impaired sucrose-induction mutants reveal the modulation of sugarinduced starch biosynthetic gene expression by abscisic acid signaling. Plant J 200I, 26:42I-433.

26. Bohnert $\mathrm{H}$ J, Nelson DE, Jensen RG: Adaptations to environmental stresses. Plant Cell 1995, 7:1099-IIIII.

27. Verslues PE, Sharp RE: Proline accumulation in maize (Zea mays L.) primary roots at low water potentials. II. Metabolic source of increased proline deposition in the elongation zone. Plant Physiol 1999, 1 19:1349-1360.

28. Saab IN, Sharp RE, Pritchard J: Effect of inhibition of ABA accumulation on the spatial distribution of elongation in the primary root and mesocotyl of maize at low water potentials. Plant Physiol 1992, 99:26-33.

29. Saab IN, Sharp RE, Pritchard J, Voetberg GS: Increased endogenous abscisic acid maintains primary root growth and inhibits shoot growth of maize seedlings at low water potentials. Plant Physiol 1990, 93:1329-1336.

30. Sharp RE, Wu Y, Voetberg GS, Saab IN, LeNoble ME: Confirmation that abscisic acid accumulation is required for maize primary root elongation at low water potentials. J Exp Bot 1994 , 45:743-75I.

31. Sharp RE: Interaction with ethylene: changing views on the role of abscisic acid in root and shoot growth responses to water stress. Plant Cell Environ 2002, 25:2II-222.

32. Kim K-N, Cheong YH, Grant JC, Pandey GK, Luan S: CIPK3, a calcium sensor-associated protein kinase that regulates abscisic acid and cold signal transduction in Arabidopsis. Plant Cell 2003, 15:4II-423.

33. Saez A, Apostolova N, Gonzalez-Guzman M, Gonzalez-Garcia MP, Nicolas C, Lorenzo O, Rodriguez PL: Gain-of-function and lossof-function phenotypes of the protein phosphatase $2 \mathrm{C} \mathrm{HABI}$ reveal its role as a negative regulator of abscisic acid signaling. Plant J 2004, 37:354-369.

34. Yoshida T, Nishimura N, Kitahata N, Kuromori T, Ito T, Asami T, Shinozaki K, Hirayama T: ABA-Hypersensitive Germination3 encodes a protein phosphatase 2C (AtPP2CA) that strongly regulates abscisic acid signaling during germination among Arabidopsis PP2Cs. Plant Physiol 2006, I 40: I I5- 126.

35. Merlot S, Gosti F, Guerrier D, Vavasseur A, Giraudat J: The ABII and $A B I 2$ protein phosphatases $2 C$ act in a negative feedback 
regulatory loop of the abscisic acid signaling pathway. Plant J 200I, 25:295-303

36. Hobo T, Kowyama Y, Hattori T: A bZIP factor, TRAB I, interacts with VPI and mediates abscisic acid-induced transcription. Proc Natl Acad Sci USA 1999, 96: I5348-15353.

37. Ito Y, Katsura K, Maruyama K, Taji T, Kobayashi M, Seki M, Shinozaki $\mathrm{K}$, Yamaguchi-Shinozaki K: Functional analysis of rice DREB I/ CBF-type transcription factors involved in cold-responsive gene expression in transgenic rice. Plant Cell Physiol 2006, 47:14I-153.

38. Rabbani MA, Maruyama K, Abe H, Khan MA, Katsura K, Ito Y, Yoshiwara K, Seki M, Shinozaki K, Yamaguchi-Shinozaki K: Monitoring expression profiles of rice genes under cold, drought, and high-salinity stresses and abscisic acid application using cDNA microarray and RNA gel-blot analyses. Plant Physiol 2003, I 33:1755-1767.

39. Xie Q, Guo H-S, Dallman G, Fang S, Weismann AM, Chua N-H: SINAT5 promotes ubiquitin-related degradation of NACI to attenuate auxin signals. Nature 2002, 419:167-170.

40. Florack DEA, Stiekema WJ: Thionins: properties, possible biological roles and mechanisms of action. Plant Mol Biol 1994 26:25-37.

4I. Spollen WG, LeNoble ME, Samuels TD, Bernstein N, Sharp RE: Abscisic acid accumulation maintains maize primary root elongation at low water potentials by restricting ethylene production. Plant Physiol 2000, 122:967-976.

42. Wu Y, Sharp RE, Durachko DM, Cosgrove DJ: Growth maintenance of the maize primary root at low water potentials involves increases in cell-wall extension properties, expansin activity, and wall susceptibility to expansins. Plant Physiol 1996, I I I:765-772.

43. Wu Y, Spollen WG, Sharp RE, Hetherington PR, Fry SC: Root growth maintenance at low water potentials: increased activity of xyloglucan endotransglycosylase and its possible regulation by abscisic acid. Plant Physiol 1994, 106:607-615.

44. Wu $Y$, Thorne ET, Sharp RE, Cosgrove DJ: Modification of expansin transcript levels in the maize primary root at low water potentials. Plant Physiol 200I, I 26: | 47|-| 479.

45. Cosgrove DJ, Bedinger P, Durachko DM: Group I allergens of grass pollen as cell wall-loosening agents. Proc Natl Acad Sci USA 1997, 94:6559-6564.

46. Levy I, Shani Z, Shoseyov O: Modification of polysaccharides and plant cell wall by endo- I,4-beta-glucanase and cellulose-binding domains. Biomol Eng 2002, 19:17-30.

47. Zhu J, Chen S, Alvarez S, Asirvatham VS, Schachtman DP, Wu Y, Sharp RE: Cell wall proteome in the maize primary root elongation zone. I. Extraction and identification of water soluble and lightly ionically-bound proteins. Plant Physiol 2006 140:31|-325.

48. Kim JB, Olek AT, Carpita NC: Cell wall and membrane-associated exo-beta-D-glucanases from developing maize seedlings. Plant Physiol 2000, I 23:47| I-486.

49. Ober ES, Sharp RE: Electrophysiological responses of maize roots to low water potentials: relationship to growth and ABA accumulation. J Exp Bot 2003, 54:813-824.

50. Brown MH, Paulsen IT, Skurray RA: The multidrug efflux protein NorM is a prototype of a new family of transporters. Mol Microbiol 1998, 31:393-395.

5I. Diener AC, Gaxiola RA, Fink GR: Arabidopsis ALF5, a multidrug efflux transporter gene family member, confers resistance to toxins. Plant Cell 200I, 13:1625-1638.

52. Uhde-Stone C, Zinn KE, Ramirez-Yanez M, Li A, Vance CP, Allan DL: Nylon filter arrays reveal differential gene expression in proteoid roots of white lupin in response to phosphorus deficiency. Plant Physiol 2003, I 3 I: 1064-1079.

53. Rogers $\mathrm{EE}$, Guerinot ML: FRD3, a member of the multidrug and toxin efflux family, controls iron deficiency responses in Arabidopsis. Plant Cell 2002, I4:1787-I799.

54. Osawa H, Stacey G, Gassmann W: ScOPTI and AtOPT4 function as proton-coupled oligopeptide transporters with broad but distinct substrate specificities. Biochem J 2006, 393:267-275.

55. Berdy SE, Kudla J, Gruissem W, Gillaspy GE: Molecular characterization of At5PTase I, an inositol phosphatase capable of terminating inositol trisphosphate signaling. Plant Physiol 200I, | 26:80|-8|0.
56. Lemtiri-Chlieh F, MacRobbie EAC, Brealey CA: Inositol hexakisphosphate is a physiological signal regulating the $\mathrm{K}^{+}$-inward rectifying conductance in guard cells. Proc Natl Acad Sci USA 2000, 97:8687-8692

57. Burnette RN, Gunesekera BM, Gillaspy GE: An Arabidopsis inositol 5-phosphatase gain-of-function alters abscisic acid signaling. Plant Physiol 2003, 132:101 I-1019.

58. Hübel F, Beck E: Plant Physiol 1996, I I 2: |429- 1436.

59. Maugenest S, Martinez I, Godin B, Perez P, Lescure AM: Structure of two maize phytase genes and their spatio-temporal expression during seedling development. Plant Mol Biol I999, 39:502-5|4

60. Hukin D, Doering-Saad C, Thomas CR, Pritchard J: Sensitivity of cell hydraulic conductivity to mercury is coincident with symplasmic isolation and expression of plasmalemma aquaporin genes in growing maize roots. Planta 2002, 215:1047-1056.

6I. Goodger JQD, Sharp RE, Marsh EL, Schachtman DP: Relationships between xylem sap constituents and leaf conductance of well-watered and water-stressed maize across three xylem sap sampling techniques. J Exp Bot 2005, 56:2389-2400.

62. Garcia O, Bouige P, Forestier C, Dassa E: Inventory and comparative analysis of rice and arabidopsis ATP-binding cassette (ABC) systems. J Mol Biol 2004, 343:249-265.

63. Held BM, Wang H, John I, Wurtele ES, Colbert JT: An mRNA putatively coding for an O-methyltransferase accumulates preferentially in maize roots and is located predominantly in the region of the endodermis. Plant Physiol 1993, 102:100 I-1008.

64. Baluška F, Parker JS, Barlow PW: A role for gibberellic acid in orienting microtubules and regulating cell growth polarity in the maize root cortex. Planta 1993, 191:149-157.

65. Boyer JS, Knipling EB: Isopiestic technique for measuring leaf water potentials with a thermocouple psychrometer. Proc Nat Acad Sci USA 1965, 54: 1044-105I.

66. Maize Oligonucleotide Array Project [http://www.maizear ray.org]

67. The Maize Root Genomics Project [http://rootgenom ics.rnet.missouri.edu/prgc/index.html]

68. Messing J, Bharti AK, Karlowski WM, Gundlach H, Kim HR, Yu Y, Wei F, Fuks G, Soderlund C, Mayer KFX, Wing RA: Sequence composition and genome organization of maize. Proc Natl Acad Sci USA 2004, I0I: I 4349-14354.

69. Gardiner JM, Buell CR, Elumalai R, Galbraith DW, Henderson DA, Iniguez AL, Kaeppler SM, Kim JJ, Liu J, Zheng L, Chandler VL: Design, production, and utilization of long oligonucleotide microarrays for expression analysis in maize. Maydica 2005, 50:425-435.

70. National Center for Biotechnology Information [http:// www.ncbi.nlm.nih.gov]

71. Universal Protein Resource [http://www.pir.uniprot.org

72. The Arabidopsis Information Resource [http://www.arabidop sis.org]

73. Wolfinger RD, Gibson G, Wolfinger ED, Bennett L, Hamadeh $H$ Bushel P, Afshari C, Paules RS: Assessing gene significance from cDNA microarray expression data via mixed models. J Comput Biol 200I, 8:625-637.

74. Chan AP, Pertea G, Cheung F, Lee D, Zheng L, Whitelaw C, Pontaroli AC, SanMiguel P, Yuan Y, Bennetzen J, Barbazuk WB, Quackenbush J, Rabinowicz PD: The TIGR Maize Database. Nucleic Acids Res 2006, 34:D77I-D776 [http://maize.tigr.org]

75. Ouyang S, Zhu W, Hamilton J, Lin H, Campbell M, Childs K, ThibaudNissen F, Malek RL, Lee Y, Zheng L, Orvis ], Haas B, Wortman J, Buell CR: The TIGR Rice Genome Annotation Resource: improvements and new features. NAR 35 Database Issue 2007:D846-85I [http://www.tigr.org/tdb/e2kl/osal/index.shtml]

76. Higo $\mathrm{K}$, Ugawa $\mathrm{Y}$, Iwamoto $\mathrm{M}$, Korenaga $\mathrm{T}$ : Plant cis-acting regulatory DNA elements (PLACE) database. Nuc Aci Res 1999 27:297-300 [http://www.dna.affrc.go.jp/PLACE/index.html]. 